Research Article

\title{
Transportation Infrastructure Project Financing; Highways Capital Structure Design Techniques
}

\author{
Hanieh Soleymani $\left(\mathbb{D},{ }^{1}\right.$ Mehdi Ravanshadnia $\left(\mathbb{D},{ }^{1}\right.$ and Mehdi Montazer ${ }^{2}$ \\ ${ }^{1}$ Department of Construction Engineering and Management, Faculty of Civil Engineering, Science and Research Branch, \\ Islamic Azad University, Tehran, Iran \\ ${ }^{2}$ Department of Law, Damavand Branch, Islamic Azad University, Damavand, Iran
}

Correspondence should be addressed to Mehdi Ravanshadnia; ravanshadnia@srbiau.ac.ir

Received 31 July 2021; Revised 19 August 2021; Accepted 25 August 2021; Published 18 October 2021

Academic Editor: S. Mahdi S. Kolbadi

Copyright (c) 2021 Hanieh Soleymani et al. This is an open access article distributed under the Creative Commons Attribution License, which permits unrestricted use, distribution, and reproduction in any medium, provided the original work is properly cited.

\begin{abstract}
Whether a private bidder can win a concession depends largely on advanced financial engineering techniques, numerous methods were developed. Meeting large infrastructure needs including its proper maintenance and operation is and will remain a major challenge for the all-around the in the coming years requiring targeted innovative financing mechanisms. Even though it is recognized that there are three types of financial instruments, equity, mezzanine finance and debt in funding an infrastructure project, the status quo is that previous capital optimization methods did not consider mezzanine finance or simply categorized it into debt-like or equity-like instruments. The global infrastructure sector is witnessing a steady growth of private equity investment in mezzanine instruments. The frequent usage of the contingent claim embedded in mezzanine financing makes the traditional model for capital structure optimization invalid. This study presents a more advanced method to optimize capital structure in infrastructure financing. This easily implemented method is based on a two-stage procedure: I) identification of optimal stopping time for convertible securities, and II) capital structure optimization by a conventional model. The quantitative optimization model can be easily generalized. The global infrastructure sector is witnessing the continued growth of a private equity fund of mezzanine tools. Repeated use of potential claims embedded in mezzanine financing has invalidated the traditional model for optimizing capital structure.
\end{abstract}

\section{Introduction}

Governments have traditionally used their budget resources for many years to do activities and projects. But, increasing need to build and manage infrastructure projects, have always been a big challenge along with a lack of funding to realize them [1]. This large limitation on one of the most important resources needed to do projects, has led owners and even contractors to supply these resources in different ways [2]. Public owners of infrastructure projects that originally bore the brunt of infrastructure financing with a variety of infrastructure financing structures have to face a daunting challenge of balancing the need for high costs and limited budgets [3]. So, states around the world are looking for new alternatives economically efficient [4]. This project offers a few quantities strategies that can facilitate the presence of private investors in infrastructure financing. One of the basic preconditions for the success of any project is access to sufficient and timely resources, proper management of financial resources, and their optimal use [5]. This is so important that without sufficient financial and timely resources, the project will not be implemented or not achieve its predetermined goals [6]. Development of adequate and efficient transport infrastructure is one of the immediate priorities of all SADC member States, just as is the case for any country, especially the developing countries [7]. Such infrastructure is key to facilitating the realisation of the aspirations for rapid economic and social development 
necessary for uplifting the standards of living of the citizens and, hence, eradication of poverty [8].

Optimization of the Public-Private Partnership (PPP) strategies for private bidders to ensure the economic justification of the investment [9]. Optimization of the capital structure has been a concern for financial designers during decades. Although the topics of financial theory have fully explored how to optimize the capital structure in corporate finance [10]. Thus, the challenge of infrastructure capital structuring is based on a combination of financial instruments pillars including stock, debt and mezzanine capital [11]. In freeway projects toll revenues are the main source of repayment of project loans and debts, distribution of project shares, and the financing for all operations and maintenance of freeway facilities [12]. Thus, an accurate and reliable estimation of traffic demand and a reduction of an effective demand risk are two vital activities that must be considered to achieve successful implementation of public-private freeway participation projects [13]. There are many quantitative methods to assess demand risk on toll roads, however, none of proposed methods have considered a comprehensive method for calculating user behaviours such as population-based behaviours and socio-economic behaviours, travel expenses, freeway communication and network efficiency, and the level of free service. None of these methods have considered the effect of agents on each other and cause and effect relationships between different agents. Demand forecasting and traffic analysis in toll freeway projects should be examined more thoroughly to consider the actual path-choosing behaviours, interactions between different agents, and their cause and effect relationships [14]. The basic options or sources available for financing infrastructure development include public financing, development assistance or grants from donors, private sector financing (by private project developers), borrowing from financing institutions (multilateral, international, regional and local) and from internally generated funds by operating institutions [15].

1.1. Literature review. To design the financing to determine the amount of project financing as a partner brought and the rest of the resources required for the project as borrowing (the range of tools is shown in Figure 1) [16]. Project borrowing refers to funds lent to the executing firm by financiers such as commercial banks, insurance companies, and retirement funds, as well as international institutions [17]. These loans are secured by project-related assets [18]. Lenders receive the principal and interest of their loans under any circumstances, whether the company makes a profit or a loss [19]. However, to ensure that there is a sufficient and strong financial capacity to repay project borrowings, lenders carefully monitor projected cash flow. Often a special form of financing called quasi-capital is used to attract risk-averse investors. For this purpose, a special type of company stock is issued called preferred stock. Paying preferred stockholders takes precedence over ordinary stockholders, but is higher than those sought by project financiers and other creditors of the company [20].

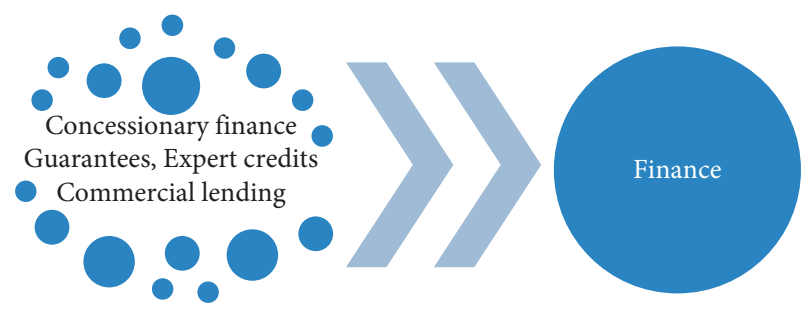

FIgURE 1: Range of financial instruments.

This group which itself has different forms, is called Mezzanine Finance. A project may use other tools such as leasing addition to borrowing methods, partners' contribution, and combined financing. Leasing is more practical in some countries [21]. Loan terms vary from bank to bank and borrower to borrower [22]. Loans may have floating/fixed interest rates [23]. Partners' contribution may be financed by project investors, investment funds, international institutions, domestic and foreign institutional investors (such as retirement funds), or the issuance of company shares in domestic/foreign stock markets (Figure 2).

The investment pyramid is a visual description of the principles by which investors should arrange their investment portfolio so that each amount of money invested has a different level of risk [24]. In this regard, the largest amount of money invested should have the least risk and a small part of the money should be invested in high risk assets. This principle ensures that people's investments do not fluctuate sharply during shocks and market downturns. The foundation of a pyramid investment includes secure and highly liquid investments; such as savings accounts or short-term deposit certificates [25]. Security and easy access to this investment can be considered as high returns, higher risk investments and lower liquidity. However, having such a base amount of available and available investments means that investors can quickly turn their investments into money when faced with unexpected costs. This prevents the sale of long-term investments or investments with low liquidity and creates costs for the investor (Figure 3).

The issue of how companies select and adjust their financial resources has been the focus of many financial economists for a long time and is still the subject of much debate [26]. Of course, once it was believed that the nature of such issues is so complex that it is not possible to formulate a reasonable theory at this time. About half a century ago opened the debate over the possibility of formulating such theories, and eventually the continuation of such debates led (Figure 4). Studies show that, since the publication of their article, various theories and models have been expressed as the capital structure of companies and how to choose it [26]. For information about related theories and patterns, see Harris and Ravio's valuable extensive work. However, research shows the agents influencing the capital structure of companies and provide a definitive answer to the following question: Why does a number of companies choose the option of issuing shares, some of them use of internal resources, and others the method of borrowing for their financing activities in different circumstances? [27, 28]. 


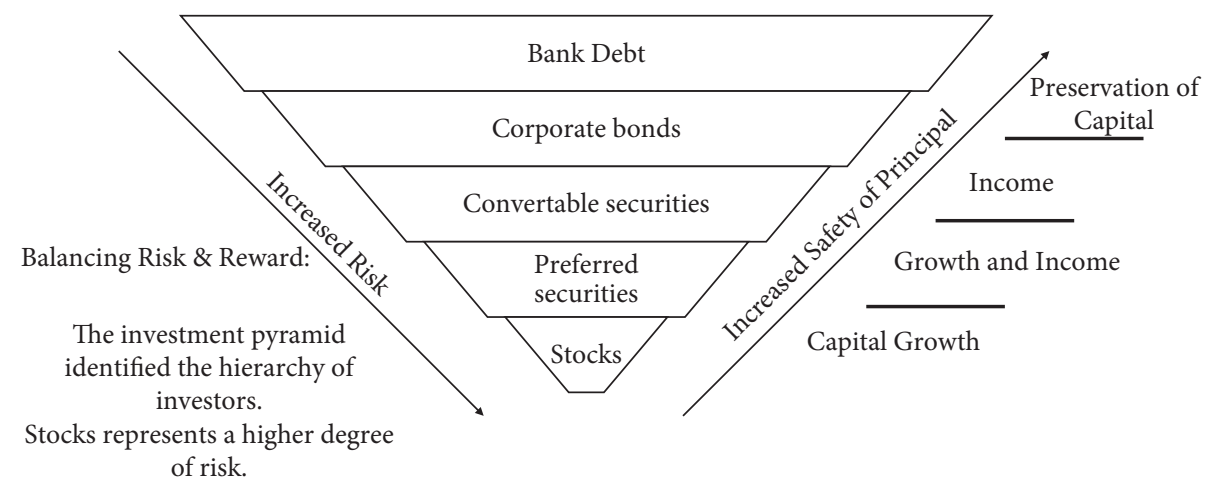

Figure 2: The investment pyramid identified the hierarchy of investors.
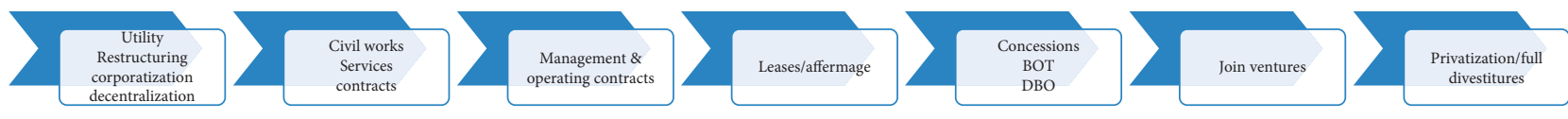

FIgURE 3: Share of private sector capital based on participation.

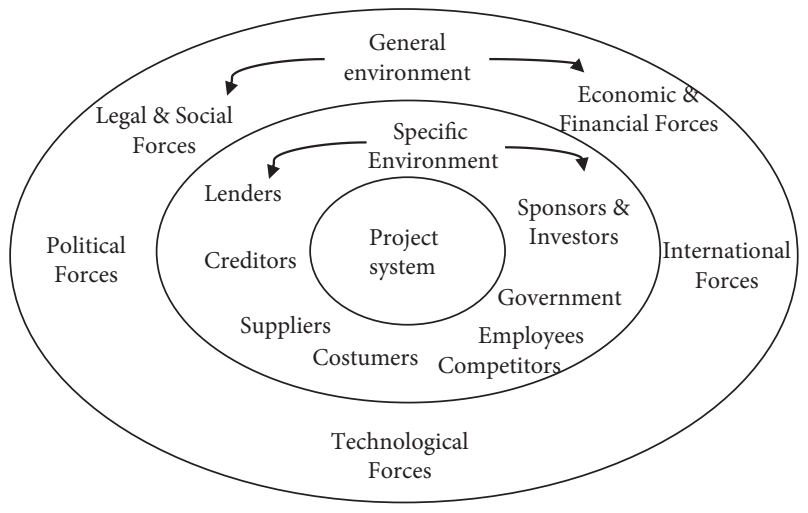

Figure 4: Analyze the business environment and make a reasonable assessment.

The next step in a pyramid scheme is investing in things like long-term certificates of deposit, government securities, and buying bonds from companies that are financially and administratively sound; these investments have a reasonable return because they pay a fixed interest rate on the money invested. The risk of losing money on these investments is also very low, but certificates of deposit and bonds have maturities, meaning that the money invested by individuals plus interest is repaid to them. Because these investments may incur losses if they arrive earlier than the due date, investors should plan not to cash them out before the due date. Shares and mutual funds can have good returns and allow investors to make significant profits by selling them at low prices as well. But a slump in the stock market reduces the value of stocks and the losses of investors. The potential return on stocks and mutual funds, as well as their risk, puts them at the top of the investment pyramid. Most people's money goes to equity stocks and mutual funds, which are considered safe investments in terms of rankings, and a small amount of people's money goes to very high-risk investments.

\section{Materials and methods}

2.1. Agent-based Modeling ( $A B M)$. Discrete event simulations and dynamic systems have long been taught in universities. Students in the fields of industry, management, economics, operations research, [28] are among the groups that simulation is taught in universities. But in the real world, there is no interaction between the groups of discrete event simulations and the groups of dynamic systems, and these two groups carry out scientific activities as two completely independent groups [2]. In recent years, factorbased modeling and simulation has become a purely academic topic. This factor-based modeling approach is able to model and simulate intelligent structures and systems and their interactions with each other, so in this report, a preliminary explanation of this type of simulation is provided. Factor-based simulation is a model involving one or more factors along with the environment in which the agents are located in a way that allows agents to interact, communicate, and make decisions [3]. In fact, an agent-centric model has a dynamic bottom-up structure [4]. This means that the activity of its components, which are agents, produces a comprehensive and coherent result, which is called the event result. These models typically encounter complex systems and issues and have innovative capabilities [5]. This makes it more difficult to identify the basic concepts and hypotheses for this approach than the System Dynamics (SD) approach. [21] states three characteristics for agents that each agent must have at least two of three characteristics as shown in Figure 5 [29].

The agent is a system that fulfills a set of goals in a complex and dynamic environment. The agent is in an environment and can sense the environment through its sensors and act on it through its operators. "Agents can be used in the role of individuals, a group of individuals, living beings, and in some cases in the role of inanimate objects such as houses and cars. There are many characteristics for agents, but what is most agreed upon and emphasized is the 


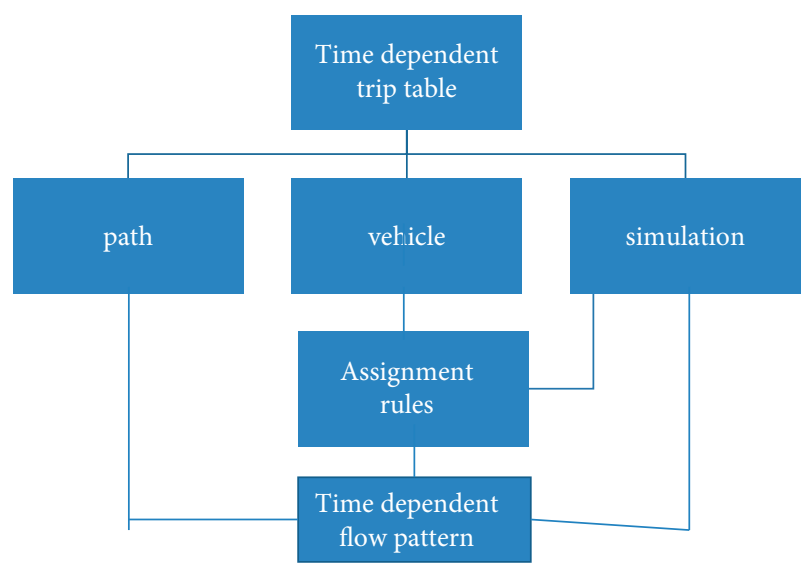

FIGURE 5: The simulation process revolves around a set of autonomous factors.

category of autonomy and decision-making power by agents. The factor-based modeling approach starts from the smallest independent and decision-making person and uses the so-called bottom-up process. The set of behaviors of each individual in relation to the environment and other people (other factors) forms a generality that can be analyzed and examined by the model. The agent-based modeling perspective is based on automation and agent-based activity. That is, a system behavior that results from the individual behavior of the system is simulated in time steps. The modeler interprets the relationships between variables and the conditions under which the system changes to a number of simple rules that can move the system from one state to another. The laws of change are actually principles that make it possible for one variable to affect another. Factor-based simulation is the best way to model where we are faced with intelligent factors such as humans. In fact, it can be said that this method is one of the best simulation methods in social and scientific environments that face a limited number or a large number of people [30].

2.1.1. Combined simulation. The interest in using a combined simulation approach, given the nature and variety of combined simulation models, there are few guidelines for modelers [31]. Combined simulation models are needed in difficult situations to create more realistic models [32]. While a system may only be modeled by a simulation approach, a combined simulation approach can be developed to increase the model effectiveness and transparency. The growing interest in combined simulation methods can be attributed to advances in simulation training [17]. Combined simulation work in the manufacturing industry focuses on the potential benefits that the manufacturing industry obtains them from a combined simulation [33]. Combined systems can be modeled on different ways by combining different basic model structures to achieve different goals [34]. These models present complementary approaches to simulation [35]. Combined modeling in the manufacturing industry seeks to consider complex behavior of manufacturing systems [36]. However, to consider complex behavior of manufacturing systems, the combined modeling framework must be able to consider all types of interactions within the combined model, and assist the model manufacturer, well-defined and understandable combined model designs to create. (SM [37].

\section{Analysis and discussion}

3.1. Stochastic capital structure in infrastructure financing. Project or infrastructure financing is a financing method of large-scale projects with large capital volumes, long-term financial constraints with limited or no recourse, implemented through a franchise business (SMS [38]. The general structure of the agent-based simulation framework shown below with the proposed model of agent-based traffic simulation can be done at a more complete level according to the simulation scheduling steps and traffic activities (Figure 6). Traditionally, ordinary capital is provided through loans or shares in private infrastructure financing. Debt financing can include bank debt, financing through bond issuers, or both [39]. While bank debt is a common tool for infrastructure financing, bonds are another popular tool for fixed income debt in an infrastructure project financing. Although most of the stock is financed by foreign shareholders such as commercial banks and credit companies but project developers need to provide more capital stock to show their ability and commitment to the project (Figure 7). Investors' stock returns often take the form of dividends, or shareholders can cash their dividends by selling their ordinary shares to other shareholders before the end of the concession.

3.2. Optimization of capital structure in infrastructure financing. In 2020, Zhang proposed a similar but more quantitative model to optimize the capital structure of public-private infrastructure projects, considering the future cash flow uncertainty of the operating period. The central methodology of these two studies, according to a win-win principle, is to provide a maximum of investors' stock returns, just like the principle and interest of lenders. In other words, from the point of view of stock investors, the optimal capital structure is considered to be a combination of stocks and debts, which maximizes the Net Present Value (NPV) of the project by removing barriers of the project risk and analysing the justification and financial sustainability of the project. From the point of view of financial models, the optimization problem of a certain capital structure creates a kind of cycle in calculations: the amount of Earnings before Interest and Taxes (EBIT) before determining a quantity of financial instruments is not clear. This problem can be solved by trial and error as shown in the Figure 8.

3.3. Optimization of the stochastic capital structure. Increasing profits in PPPs have revolutionized the use of mezzanine financial instruments to finance infrastructure around the world for private stock investors. Thus, according to its various aspects, capital resources can be divided into quasi-equity capital (such as preferred stock), 

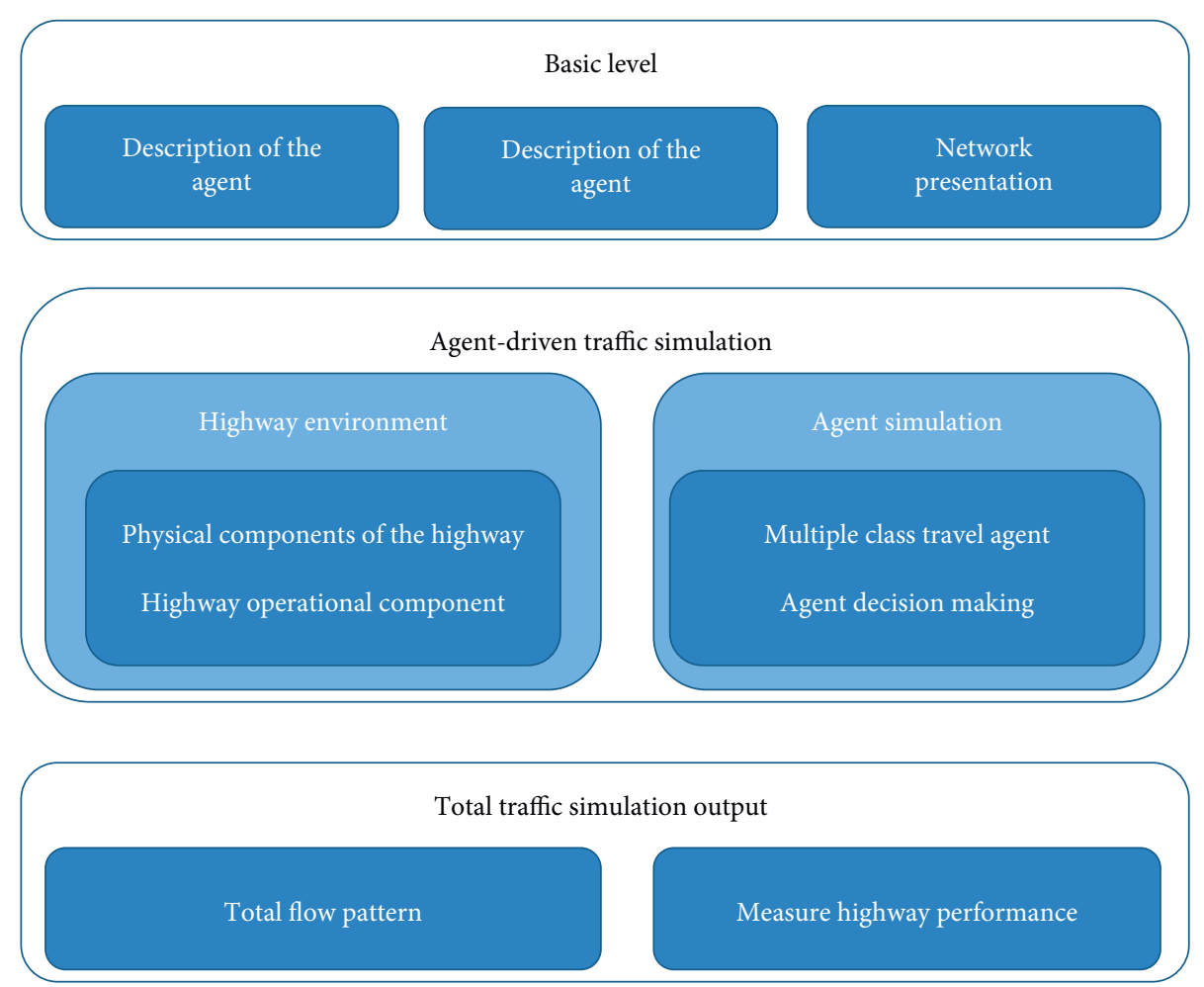

FIGURE 6: The general structure of the factor-based simulation framework shown by the proposed traffic simulation model.

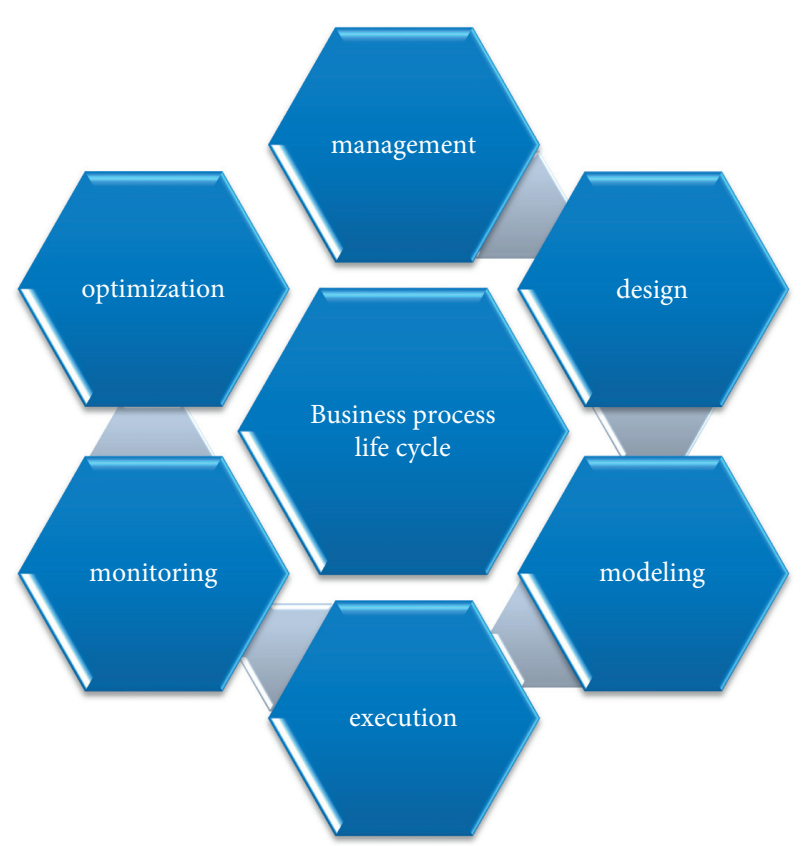

Figure 7: The general trend of stochastic capital structure in infrastructure financing.

$L_{E}$, quasi-debt capital (such as project securities), $L_{D}$, and convertible capital (such as convertible securities), $L_{M}$, respectively. In the following, a more advanced method is proposed to optimize the stochastic capital structure by entering Stockpile Disposal Program/Semi-definite Program (SDP) to identify the stochastic optimal capital structure.

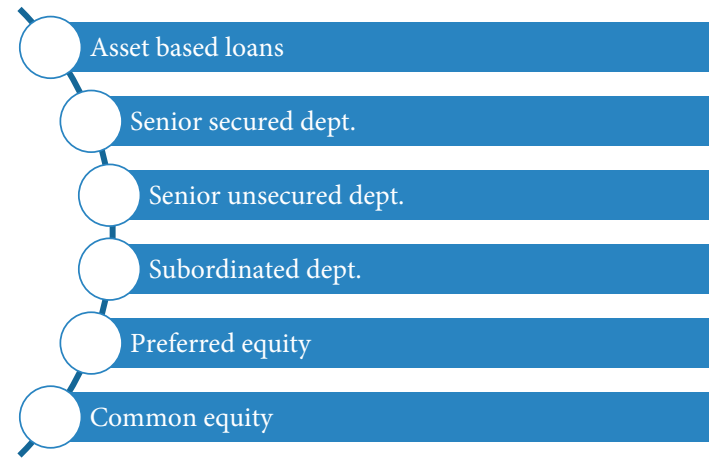

FIGURE 8: The general trend of optimization of capital structure in infrastructure financing.

Despite identification of the dynamic stopping time, the optimization process of a certain capital structure changes to two optimization stages of the stochastic capital structure in Figure 9.

3.4. Identifying the optimal stopping time with SDP. During the year $\tau_{k}$, the holder of convertible securities decides on the application of long-term debt transfer to shares. The holder can appear as a shareholder when the outstanding debt is less than the expected conditional value of future earnings. Suppose that the conversion rate, $K_{j}$, in year $j$ is clearly specified at the beginning of the contract, and the shareholder can only receive his interest through dividends. If the holder of convertible securities decides to apply the right in the year $\tau_{k}$, the amount of the share that the 


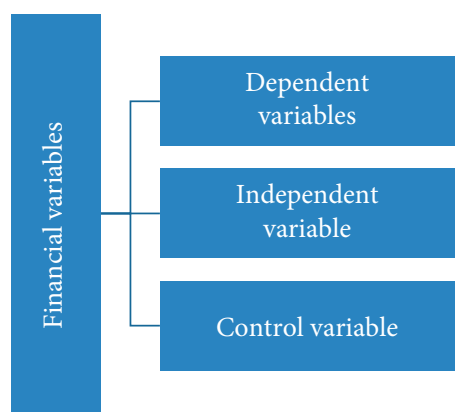

FIGURE 9: The general trend of optimization of the stochastic capital structure.

stakeholder can have in the simulation path $k$ is equal to $Q_{\tau_{k}}$ and calculated by the equation 2. So, the NPV of dividends he can collect is calculated by equation 7 . In a year $\tau_{k}$, the holder of convertible bonds only needs to compare his outstanding loan with the expected conditional value of the equation 8 .

$$
\begin{aligned}
Q_{\tau_{k}}= & \sum_{j=\tau_{k}}^{T} \frac{P_{j}^{M}}{K_{\tau_{k}}}, \\
S_{\tau_{k}}= & \sum_{j=\tau_{k}}^{T} \operatorname{NAC}_{(j, k)} \cdot e^{-r_{e} \cdot\left(j-\tau_{k}\right)} \cdot \frac{Q_{\tau_{k}}}{\sum\left(L_{E} \cdot C_{P}^{i}\right)+Q_{\tau_{k}}}, \\
& \operatorname{Max}\left[\left\{\sum_{\tau_{k}}^{T}\left(P_{j}^{M}\right)\right\}, E\left[S_{\tau_{k}} \mid F_{\tau_{k}}\right]\right],
\end{aligned}
$$

Where $F_{\tau_{k}}$ is available information of the holder of convertible bonds in the year $\tau_{k}$. Thus, when the expected conditional value of convertible bonds is not more than the outstanding debt, the holder will choose to apply his conversion right. One of the drawbacks of combining Multiple Complex System (MCS) with SDP is that NPV dividends are not exactly measurable. This is because SDP estimates the continuing value, determines a non-optimal action strategy, and therefore naturally offers a lower price range. One method for estimating the continuing value is using a regression-based approach, such as the Least Squares Method (LSM) method. The basic idea behind the LSM is that conditional expectation, $E\left[S_{\tau_{k}} \mid F_{\tau_{k}}\right]$ can be approximated in each year of application with least squares regression along with MCS cross-sectional data. Indeed, in the year $\tau_{k}$, $E\left[S_{\tau_{k}} \mid F_{\tau_{k}}\right]$ can be represented as a linear combination of basic orthonormal functions, $p_{i}\left(\operatorname{EBIT}_{(j \cdot k}\right)$ such as the Power, Laguerre, Hermite, and Legendre polynomials.

$$
\begin{aligned}
E\left[S_{\tau_{k}} \mid F_{\tau_{k}}\right] & =\sum_{i=0}^{\infty} a_{i} p_{i}\left(\operatorname{EBIT}_{\left(\tau_{k}, k\right)}\right), \\
\left\{\hat{a}_{i=1, \ldots, Z}\right. & =\left\|\sum_{i=0}^{Z} a_{i} p_{i}\left(\operatorname{EBIT}_{\left(\tau_{k}, k\right)}\right)-S_{\tau_{k}}\right\|^{2},
\end{aligned}
$$

$$
\begin{aligned}
\mathrm{NPV}^{O p t}\left(L_{E}^{O p t}, L_{D}^{O p t}, L_{M}^{O p t}\right)= & \max \left\{\operatorname{NPV}\left(L_{E}, L_{D}, L_{M}\right)\right\} \forall \\
& \cdot\left(L_{E}, L_{D}, L_{M}\right) .
\end{aligned}
$$

\section{Conclusion}

The most important risk in projects implemented with a PPP system and for which non-recourse or limited recourse financing (project or structured) is considered, is the risk of revenue based on traffic demand. A demand forecast can be considered as the most important part of the planning stage of road PPP projects. Traffic demand is a direct determinant directly related to revenue levels and toll rates. Optimistic traffic forecast in many projects has led to many problems in the financial structure of projects. Sometimes, optimistic forecast along with a traffic level has had irreversible effects in early years of the project. Demand forecast will include several evaluation methods which will used various economic and social parameters, network road conditions, and various design pattern changes to predict the traffic level of the transportation system. Demand forecast is a difficult activity that requires a lot of studies. For strategic project planning, the feasibility of alternative strategies and demand for unique components of these strategies should be assessed at predictions. In corridor planning, in the forecasting process, the adequacy and quality of the service with current facilities as well as potential needs for promoting these facilities should be evaluated. To plan facilities, in the forecasting process, the capacity of new facilities that may be built or the capacity of existing road facilities, should be evaluated. This study has offered a framework in order to present available generic and specific benefits to each project stakeholder, and it provides the required motivation for project owners to use and implement it in their future projects. As a result, in short, whether a private company can earn a project credit depends heavily on the capital cost of a private infrastructure project. With advanced financial engineering techniques, several methods have been developed to find the right combination of stocks and debts. Although three types of financial instruments including stock, mezzanine, and debt are defined in the infrastructure financing project. The current situation is such that the usual optimization methods of mezzanine financing are not considered or simply considered as quasi-equity or quasi-debt. Accordingly, constructability improvements have become the concern of construction industry practitioners. Considering constructability issues in the early stages of the project enhances identifying design limitations that prevent capabilities of contractors to take part in planning and improving project performance. The purpose of this study is identifying the prerequisites of constructability to resolve the current problems of projects, including inappropriate plans without implement ability, poor decision making in design, and lack of sufficient implementation experience in the design engineering team. 


\section{Data Availability}

Requests for access to these data should be made to [the corresponding author email address: ravanshadnia@ srbiau.ac.ir].

\section{Conflicts of Interest}

The author(s) declare(s) that there is no conflict of interest regarding the publication of this paper.

\section{Acknowledgments}

An Acknowledgements section is optional and may recognise those individuals who provided help during the research and preparation of the manuscript.

\section{References}

[1] C. Li, L. Hou, B. Sharma et al., "Developing a new intelligent system for the diagnosis of tuberculous pleural effusion," Computer Methods and Programs in Biomedicine, vol. 153, pp. 211-225, 2018.

[2] M. Wang, C. Huiling, Y. Bo et al., "Toward an optimal kernel extreme learning machine using a chaotic moth-flame optimization strategy with applications in medical diagnoses," Neurocomputing, vol. 267, pp. 69-84, 2017.

[3] J. Xia, C. Huiling, Li Qiang et al., "Ultrasound-based differentiation of malignant and benign thyroid Nodules: an extreme learning machine approach," Computer Methods and Programs in Biomedicine, vol. 147, pp. 37-49, 2017.

[4] H.-L. Chen, W. Gang, Ma Chao, C. Zhen-Nao, L. Wen-Bin, and W. Su-Jing, "An efficient hybrid kernel extreme learning machine approach for early diagnosis of Parkinson's disease," Neurocomputing, vol. 184, pp. 131-144, 2016.

[5] L. Shen, L. Xin-Yuan, and H. Min, "Evolving support vector machines using fruit fly optimization for medical data classification," Knowledge-Based Systems, vol. 96, pp. 61-75, 2016.

[6] L. Hu, G. Hong, J. Ma, X. Wang, and H. Chen, "An efficient machine learning approach for diagnosis of paraquat-poisoned patients," Computers in Biology and Medicine, vol. 59, pp. 116-124, 2015.

[7] R. Samimpey and E. Saghatforoush, "A systematic review of prerequisites for constructability implementation in infrastructure projects," Civil Engineering Journal, vol. 6, no. 3, pp. 576-590, 2020.

[8] M. Alinezhad, S. Ehsan, K. Zahra, and P. Christopher, "Analysis of the benefits of implementation of IPD for construction project stakeholders," Civil Engineering Journal, vol. 6, pp. 1609-1621, 2020.

[9] X. Xu and H.-L. Chen, "Adaptive computational chemotaxis based on field in bacterial foraging optimization," Soft Computing, vol. 18, no. 4, pp. 797-807, 2014.

[10] Y. Zhang, L. Renjing, A. H. Ali et al., "Towards augmented kernel extreme learning models for bankruptcy prediction: algorithmic behavior and comprehensive analysis," Neurocomputing, 2020.

[11] J. Hu, C. Huiling, A. H. Ali et al., "Orthogonal learning covariance matrix for defects of grey wolf optimizer: insights, balance, diversity, and feature selection," Knowledge-Based Systems, vol. 213, Article ID 106684, 2021.

[12] J. E. Schaufelberger and I. Wipadapisut, "Alternate financing strategies for build-operate-transfer projects," Journal of
Construction Engineering and Management, vol. 129, no. 2, pp. 205-213, 2003.

[13] X. Wang and K. M. Kockelman, "Forecasting network data: spatial interpolation of traffic counts from Texas data," Transportation Research Record, vol. 1, pp. 100-108, 2105.

[14] X. Li, H. Yang, J. Zhang, G. Qian, H. Yu, and J. Cai, "Timedomain analysis of tamper displacement during dynamic compaction based on automatic control," Coatings, vol. 11, no. 9, 2021.

[15] A. Pilvere-Javorska and I. Pilvere, "European nordic countries stock market listed companies': factor and cluster analysis approach," Emerging Science Journal, vol. 4, pp. 443-453, 2020.

[16] E. R. Yescombe, Public-Private Partnerships: Principles of Policy and Finance, Elsevier: Butterworth-Heinemann, Oxford, UK, 2007.

[17] J. Tu, "Evolutionary biogeography-based Whale optimization methods with communication structure: towards measuring the balance," Knowledge-Based Systems, vol. 212, Article ID 106642, 2020.

[18] Y. Bie, J. Ji, X. Wang, and X. Qu, “Optimization of electric bus scheduling considering stochastic volatilities in trip travel time and energy consumption," Computer-Aided Civil and Infrastructure Engineering, vol. 1, 2021, in Press.

[19] Y. Du, N. Pan, Z. Xu, F. Deng, Y. Shen, and H. Kang, "Pavement distress detection and classification based on YOLO network," International Journal of Pavement Engineering, vol. 1, pp. 1-14, 2020.

[20] S. Gatti, Project Finance in Theory and Practice: Designing, Structuring, and Financing Private and Public Projects, Academic Press, Cambridge, MA, USA, 2013.

[21] H. Chen, A. H. Ali, C. Huiling, W. Mingjing, P. Zhifang, and H. G. Amir, "Multi-population differential evolution-assisted Harris hawks optimization: framework and case studies," Future Generation Computer Systems, vol. 111, pp. 175-198, 2020.

[22] C. Zhang, A. Ali, and L. Sun, "Investigation on low-cost friction-based isolation systems for masonry building structures: experimental and numerical studies," Engineering Structures, vol. 243, Article ID 112645, 2021.

[23] L. Hoffman, The Law and Business of International Project Finance: A Resource for Governments, Sponsors, Lenders, Lawyers, and Project, Cambridge University Press, Cambridge, UK, 2nd edition, 2001.

[24] W. Zhou, J. Liu, J. Lei, L. Yu, and J.-N. Hwang, "GMNet: graded-feature multilabel-learning network for RGB-thermal urban scene semantic segmentation," IEEE Transactions on Image Processing, 2021.

[25] H. K. Young, Y.Yi Chih, and C. William Ibbs, "Towards a comprehensive understanding of public private partnerships for infrastructure development," California Management Review, vol. 51, 2011.

[26] M. Wang and H. Chen, "Chaotic multi-swarm whale optimizer boosted support vector machine for medical diagnosis," Applied Soft Computing, vol. 88, Article ID 105946, 2020.

[27] H. DeAngelo and L. DeAngelo, "Capital structure, payout policy, and financial flexibility," Marshall School of Business, University of Southern California, Los Angeles, CA, USA, 2006, http://ssrn.com/abstract=916093 Working Paper No. FBE 02-06.

[28] X. Zhao, X. Zhang, Z.-N. Cai et al., "Chaos enhanced grey wolf optimization wrapped ELM for diagnosis of paraquat-poisoned patients," Computational Biology and Chemistry, vol. 78, pp. 481-490, 2019. 
[29] Y. Zhang, "Boosted binary Harris hawks optimizer and feature selection," Engineering with Computers, vol. 25, p. 26, 2020a.

[30] Y. Zhang, "Towards augmented kernel extreme learning models for bankruptcy prediction: algorithmic behavior and comprehensive analysis," Neurocomputing, vol. 430, 2020.

[31] D. Zhao, L. Lei, Yu Fanhua et al., "Chaotic random spare ant colony optimization for multi-threshold image segmentation of 2D Kapur entropy," Knowledge-Based Systems, vol. 216, Article ID 106510, 2020.

[32] C. Yu, C. Mengxiang, C. Kai et al., "SGOA: annealing-behaved grasshopper optimizer for global tasks," Engineering with Computers, vol. 1, pp. 1-28, 2021.

[33] Y. Xu, C. Huiling, L. Jie, Z. Qian, J. Shan, and Z. Xiaoqin, "Enhanced Moth-flame optimizer with mutation strategy for global optimization," Information Sciences, vol. 492, pp. 181203, 2019.

[34] X. Zhao, Li Daoliang, Y. Wenzhu, and C. Guifen, "Feature selection based on improved ant colony optimization for online detection of foreign fiber in cotton," Applied Soft Computing, vol. 24, pp. 585-596, 2014.

[35] W. Shan, "Double adaptive weights for stabilization of moth flame optimizer: balance analysis, engineering cases, and medical diagnosis," Knowledge-Based Systems, vol. 214, Article ID 106728, 2020.

[36] H. Yu, Li Wenshu, C. Chengcheng et al., "Dynamic Gaussian bare-bones fruit fly optimizers with abandonment mechanism: method and analysis," Engineering with Computers, vol. 1, pp. 1-29, 2020.

[37] S. Kolbadi, S. Mohammad, M. Safi et al., "Explosive performance assessment of buried steel pipeline," Advances in Civil Engineering, vol. 2021, Article ID 6638867, 24 pages, 2021.

[38] S. Kolbadi, S. Mohammad, H. Piri, K. Ali, S. M. S. Kolbadi, and M. Mirtaheri., Seismic performance evaluation of slottedweb and bolt-flange plate moment connection," Earthquakes and Structures, vol. 20, no. 6, pp. 655-667, 2021.

[39] M. Mirtaheri, M. Salkhordeh, S. M. S Kolbadi, H. Mirzaeefard, and M. R. Razzaghian, "Evaluation of 2D concentrically braced frames with cylindrical dampers subjected to near-field earthquake ground motions," Numerical Methods in Civil Engineering, vol. 4, no. 3, pp. 21-30, 2020. 